\title{
Trends in Hospital Admission for Stroke in Calgary
}

\author{
T.S. Field, T.L. Green, K. Roy, J. Pedersen, M.D. Hill
}

\begin{abstract}
Background: Stroke incidence has fallen since 1950. Recent trends suggest that stroke incidence may be stabilizing or increasing. We investigated time trends in stroke occurrence and in-hospital morbidity and mortality in the Calgary Health Region. Methods: All patients admitted to hospitals in the Calgary Health Region between 1994 and 2002 with a primary discharge diagnosis code (ICD-9 or ICD-10) of stroke were included. In-hospital strokes were also included. Stroke type, date of admission, age, gender, discharge disposition (died, discharged) and in-hospital complications (pneumonia, pulmonary embolism, deep venous thrombosis) were recorded. Poisson and simple linear regression was used to model time trends of occurrence by stroke type and age-group and to extrapolate future time trends. Results: From 1994 to 2002, 11642 stroke events were observed. Of these, 9879 patients (84.8\%) were discharged from hospital, $1763(15.1 \%)$ died in hospital, and 591 (5.1\%) developed in-hospital complications from pneumonia, pulmonary embolism or deep venous thrombosis. Both in-hospital mortality and complication rates were highest for hemorrhages. Over the period of study, the rate of stroke admission has remained stable. However, total numbers of stroke admission to hospital have faced a significant increase $(\mathrm{p}=0.012)$ due to the combination of increases in intracerebral hemorrhage $(\mathrm{p}=0.021)$ and ischemic stroke admissions $(\mathrm{p}=0.011)$. Sub-arachnoid hemorrhage rates have declined. In-hospital stroke mortality has experienced an overall decline due to a decrease in deaths from ischemic stroke, intracerebral hemorrhage and sub-arachnoid hemorrhage. Conclusions: Although age-adjusted stroke occurrence rates were stable from 1994 to 2002, this is associated with both a sharp increase in the absolute number of stroke admissions and decline in proportional in-hospital mortality. Further research is needed into changes in stroke severity over time to understand the causes of declining in-hospital stroke mortality rates.
\end{abstract}

RÉSUMÉ: Étude des tendances dans les admissions hospitalières pouraccident vasculaire cérébral à Calgary. Introduction: L'incidence de l'accident vasculaire cérébral (AVC) a baissé depuis 1950. Les tendances récentes suggèrent que l'incidence de l'AVC se stabilise ou est à la hausse. Nous avons étudié les tendances séculaires de l'incidence de l'AVC ainsi que la morbidité et la mortalité hospitalière dans la région sanitaire de Calgary. Méthodes: Tous les patients admis à l'hôpital dans la région sanitaire de Calgary entre 1994 et 2002 et dont le dossier fait mention d'un diagnostic d'AVC (code ICD-9 ou ICD-10) à la sortie de l'hôpital ont été inclus dans l'étude. Les patients ayant subi un AVC en milieu hospitalier ont également été inclus. Des données sur le type d'AVC, la date d'admission, l'âge, le genre, le statut à la sortie (décès, congé), et les complications hospitalières (pneumonie, embolie pulmonaire, thrombose veineuse profonde) ont été colligées. L'équation de Poisson et l'analyse de régression linéaire simple ont été utilisées pour modéliser les tendances séculaires par type d'AVC et groupe d'âge et pour extrapoler les tendances futures. Résultats: De 1994 à 2002 , 11642 AVC ont été observés. 9879 patients $(84,8 \%)$ sont sortis de l'hôpital vivant, 1763 (15,1\%) sont morts à l'hôpital et 591 (5,1 \%) ont présenté des complications pendant leur hospitalisation, soit une pneumonie, une embolie pulmonaire ou une thrombose veineuse profonde. La mortalité hospitalière et le taux de complications étaient plus élevés dans l'AVC hémorragique. Pendant l'étude, le taux d'admission est demeuré stable. Cependant le nombre total d'admissions pour AVC a augmenté significativement $(\mathrm{p}=0,012)$ à cause de l'augmentation des admissions pour hémorragie intracérébrale $(\mathrm{p}=0,021)$ et pour AVC ischémique $(\mathrm{p}=0,011)$. Les taux d'hémorragie sous-arachnoïdienne ont diminué. La mortalité hospitalière due à l'AVC en général a diminué à cause d'une diminution de la mortalité due à l'AVC ischémique, à l'hémorragie intracérébrale et à l'hémorragie sous-arachnoïdienne. Conclusions: Bien que l'incidence de l'AVC ajustée pour l'âge ait été stable de 1994 à 2002, on a observé une augmentation importante du nombre absolu d'admissions pour AVC et une diminution de la mortalité hospitalière proportionnelle. Des recherches sur les changements temporels dans la sévérité de l'AVC pourront aider à comprendre les causes de la diminution des taux de mortalité hospitalière due à l'AVC.

Can. J. Neurol. Sci. 2004; 31: 387-393

The Calgary Health Region provides tertiary care to all of southern Alberta. Over the past ten years, the region has experienced rapid population growth. During this time, treatment of stroke has undergone a number of improvements, including centralization of stroke services, the introduction of stroke thrombolysis in Calgary in 1996, and the opening of a designated in-patient stroke unit at the Foothills hospital in 2001.

Epidemiological evidence since 1950 suggests that the ageadjusted incidence of stroke is declining over time. ${ }^{1}$ However,
From the Faculty of Medicine, Dalhousie University, Halifax, NS, (TSF); Calgary Stroke Program, Department of Clinical Neuroscience, (TLG, MDH), Quality Improvement and Health Information (KR, JP), Calgary Health Region; Department of Clinical Neurosciences, Department of Medicine and Department of Community Health Sciences, Faculty of Medicine, University of Calgary, (MDH) Calgary, AB Canada.

Received November 19, 2003. AcCePted infinAlform March 2, 2004. Reprint requests to: Michael D. Hill, Calgary Stroke Program, Department of Clinical Neurosciences, University of Calgary, Foothills Hospital, Rm 1242A, $140329^{\text {th }}$ Street NW, Calgary, Alberta, T2N 2T9Canada. 
stroke incidence rates may have stabilized ${ }^{2-4}$ or even increased ${ }^{5,6}$ over the last two decades and the rising proportion of elderly in western societies suggests that a larger number of overall strokes will occur despite declining or stable incidence. ${ }^{7}$

Although rates of morbidity and mortality from ischemic heart disease have declined in $\mathrm{Canada}^{8-10}$ and other industrialized nations, ${ }^{11-14}$ these trends have not been consistently reported for stroke. ${ }^{15,16}$ A recent World Health Organisation study among nine countries confirms that increasing or decreasing stroke mortality is directly attributable to changes in the case fatality rate rather than changing event rates. ${ }^{17}$ Population-based data suggest that a decline in stroke mortality, also beginning in the $1950 \mathrm{~s},{ }^{18}$ has stabilized over the last two decades. ${ }^{19}$ In-hospital morbidity from stroke, however, is less well-quantified and patterns over time are not known

The purpose of this study was to examine time trends in stroke occurrence and in-hospital morbidity and mortality in Calgary.

\section{Methods}

Administration in the Calgary Health Region is coordinated such that hospital discharge data on all patients admitted to hospitals in the region is amassed centrally. Administrative data from a nine-year period beginning January 1, 1994 and ending December 31, 2002 were examined. This period was chosen because data were centralized from this time forward for the Calgary Health Region. Only administrative records from adult facilities were used in this analysis. All patients with a discharge diagnosis code (International Classification of Diseases, 9th Revision-Clinical Modification and [ICD-9-CM]) of 36231, $430,431,43300$ to 43391,43400 to 43491,4350 to 4359,436 , or 4376 or an ICD-10 code of G450, G451, G452, G453, G458, G459, H341, I600 to I609, I610 to I619, I630 to I639 or I64 were included. Consistent with our previous work, the first diagnosis position was chosen to increase the probability that the patient had suffered a stroke on the date of admission..$^{20,21}$ In-hospital strokes were also included. Date of admission, date of inpatient discharge, hospital, age, gender, discharge disposition (died, discharged, signed out), and in-hospital complications (pneumonia, pulmonary embolism (PE) and deep venous thrombosis (DVT)) were recorded. Complications were identified using the ICD coding flags for in-hospital complications. Gender differences were not evaluated in this analysis.

Population in the Calgary Health Region is recorded by Statistics Canada every five years using national census data. Yearly population changes were estimated using the exponential growth formula and recorded population values from 1996 and 2001 census data for the Calgary Health Region. We assumed that hospital separations for stroke were a reasonable estimate of stroke occurrence rates on a population basis and therefore calculated rates compared to the Calgary population. Stroke occurrence rates were age-standardized to the 2001 Canadian population using the direct method and expressed in terms of events per 100000 person-years. Poisson regression was used to assess rate changes over time. However, because modeling was not substantially different using simple linear regression, the latter method was used to test and plot time trends of stroke occurrence by stroke type and age-group and to extrapolate future time trends when possible. Venous sinus/cortical vein thrombosis (VS/CVT) rates were so rare that year over year rates were not examined.

\section{RESUlts}

Over the nine years from 1994 to 2002, a total of 11642 admitted strokes were observed. Of these, 9879 patients were discharged or signed out $(84.8 \%)$ and 1763 died in hospital $(15.1 \%)$. There were 541 patients who developed complications in hospital from pneumonia $(4.7 \%)$ and 50 patients suffered complications from PE or DVT $(0.4 \%)$. There were 739 subarachnoid hemorrhages (SAH) (6.4\% of all strokes), 8088 ischemic strokes (69.5\%), 1717 transient ischemic attacks (TIA) (14.8\%), 1084 intracerebral hemorrhages (ICH) $(9.3 \%)$, and 14 VS/CVT $(0.1 \%) .50 .3 \%$ of patients were male. Age-adjusted stroke rates are shown in Table 1.

The average yearly in-hospital mortality rate for all strokes was $15.3 \%$. The average yearly mortality for all ischemic strokes was $14.0 \%$; TIA, $1.2 \%$; ICH, 37.3\%; SAH, 30.2\%; VS/CVT, $7.4 \%$. Both in-hospital mortality and complication rates were highest for hemorrhages. Mean rates of pneumonia and PE or deep-vein thrombosis were $8.4 \%$ and $1.0 \%$ for $\mathrm{ICH}$, and $9.3 \%$

Table 1: Age-Adjusted Stroke Admissions per 100,000 population

\begin{tabular}{lllllll}
\hline Year & ALL & AIS & VS/CVT & ICH & SAH & TIA \\
1994 & $156.6(146.5-166.7)$ & $104.9(96.6-113.3)$ & 0 & $11.1(8.4-13.8)$ & $9.8(7.4-12.1)$ & $30.9(26.3-35.4)$ \\
1995 & $210.3(199.0-221.7)$ & $145.8(136.3-155.4)$ & $0.3(0-0.7)$ & $17.6(14.3-20.9)$ & $12.5(9.8-15.1)$ & $34.2(29.5-38.8)$ \\
1996 & $186.9(176.5-197.3)$ & $130.6(121.8-139.3)$ & 0 & $18.5(15.2-21.7)$ & $11.7(9.2-14.2)$ & $26.2(22.2-30.1)$ \\
1997 & $170.3(160.7-180.0)$ & $116.5(108.5-124.5)$ & 0 & $18.6(15.4-21.8)$ & $9.1(7.1-11.2)$ & $26.1(22.3-29.9)$ \\
1998 & $167.8(158.5-177.1)$ & $119.2(111.4-127.1)$ & $0.1(0-0.3)$ & $16.4(13.4-19.3)$ & $10.2(8.0-12.4)$ & $21.9(18.5-25.3)$ \\
1999 & $179.4(170.1-188.8)$ & $125.1(117.3-132.9)$ & $0.1(0-0.4)$ & $16.1(13.3-19.0)$ & $12.1(9.8-14.5)$ & $25.9(22.4-29.5)$ \\
2000 & $162.5(153.9-171.0)$ & $117.6(110.3-124.9)$ & $0.2(0-0.5)$ & $14.8(12.3-17.4)$ & $8.8(6.9-10.8)$ & $21(17.9-24.1)$ \\
2001 & $162.1(153.8-170.4)$ & $118.9(111.7-126.1)$ & $0.6(0.1-1.0)$ & $14.8(12.3-17.3)$ & $7.9(6.1-9.7)$ & $19.9(17.0-22.9)$ \\
2002 & $145.5(137.9-153.2)$ & $100(93.6-106.4)$ & $0.2(0-0.4)$ & $14(11.6-16.4)$ & $6.0(4.5-7.5)$ & $25.3(22.1-28.5)$
\end{tabular}

$\mathrm{ALL}=$ all stroke; AIS = acute ischemic stroke; VS/CVT = venous sinus/cortical vein thrombosis; $\mathrm{ICH}=$ intracerebral hemorrhage; $\mathrm{SAH}=$ subarachnoid hemorrhage; TIA = transient ischemic attack.

Rates are standardized using the direct method to the 2001 Canadian population. 


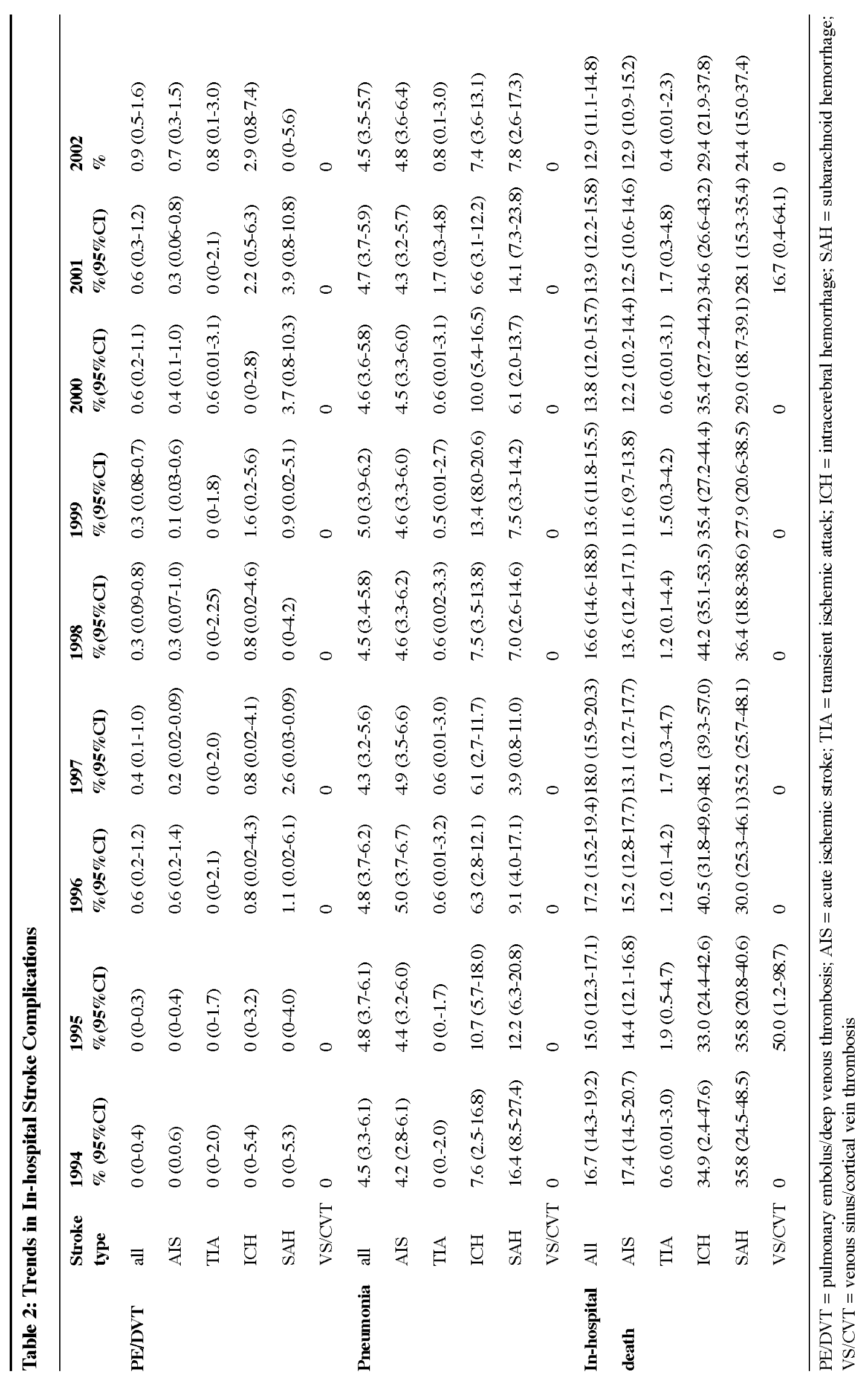




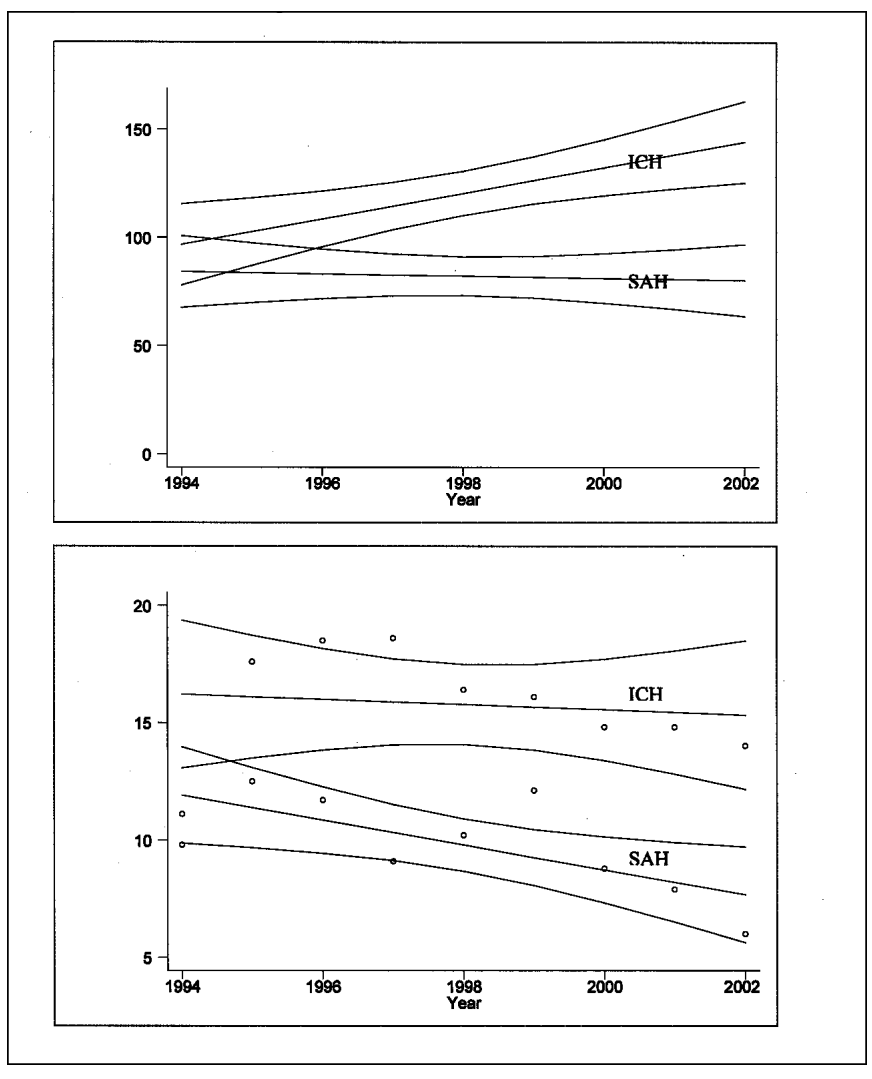

Figure 1: Trends in Hemorrhage

Panel A shows absolute numbers of stroke admissions by hemorrhage type. The curved lines represent $95 \%$ confidence bands around the regression lines. The rising absolute numbers of ICH is statistically different from $0(p=0.021)$.

Panel B shows age-adjusted stroke occurrence rates per 100000 population. Only the age adjusted SAH rate is statistically significantly declining over time $(p=0.042)$.

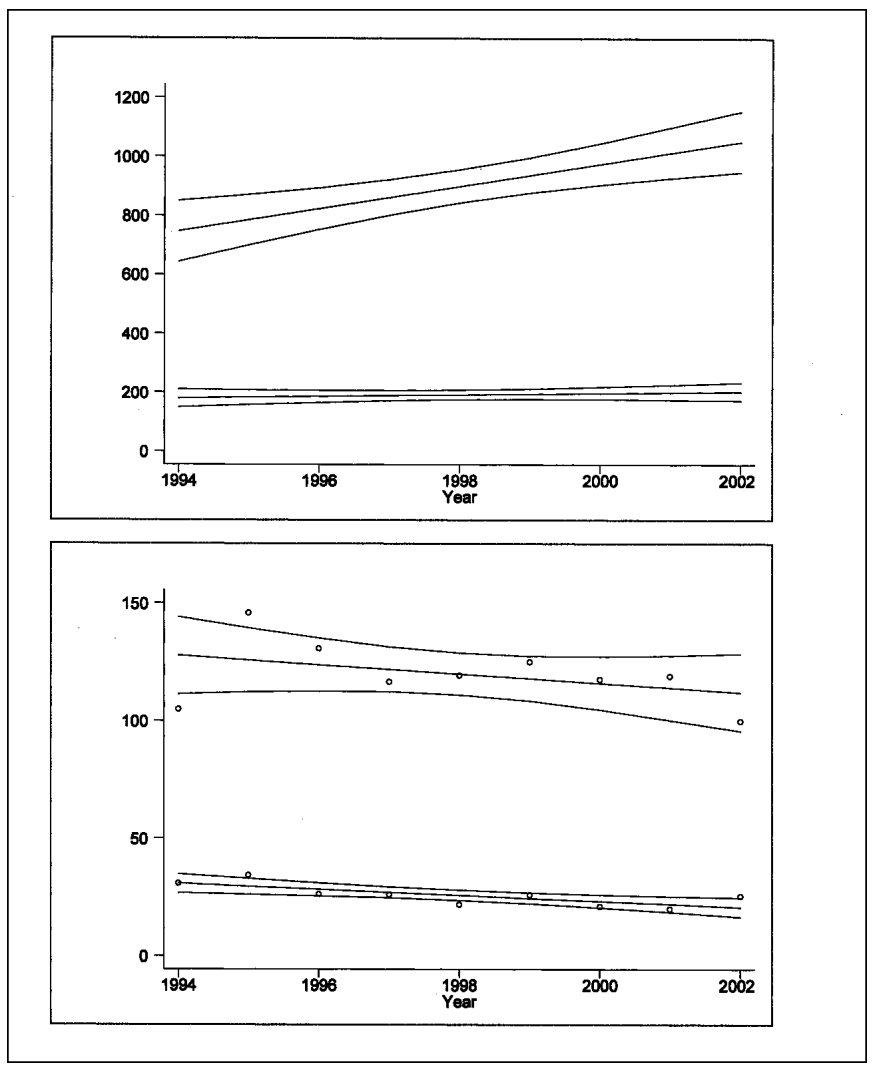

Figure 2: Trends in Ischemic Stroke and TIA

Panel A: The top line represents the sharply rising number of ischemic strokes admitted to hospital annually. The rising slope is significantly different from $0(p=0.011)$. The lower line represents the number of TIAs admitted to hospital.

Panel B: The top line represents the age-adjusted rate of ischemic stroke admissions per 100000 population. The rate is unchanged over time ( $p=0.288)$. The bottom line represents the age-adjusted rate of TIA admissions per 100000 population. The rate shows decreasing TIA admissions $(p=0.020)$.

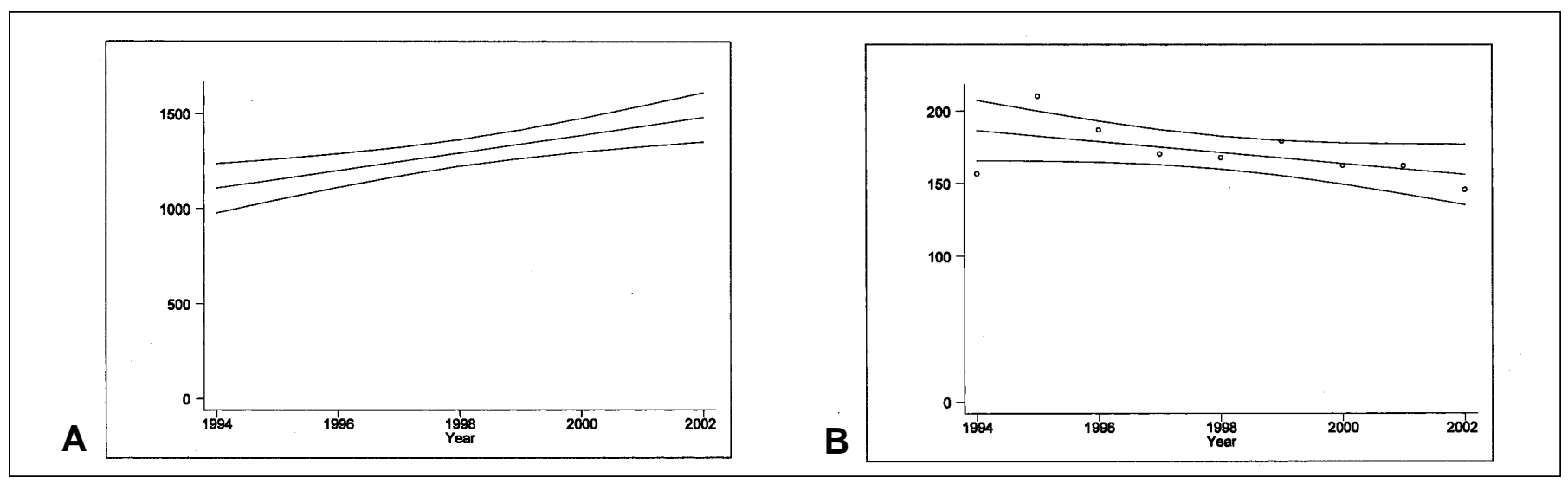

Figure 3: Trends in All Stroke

Panel A shows the total numbers of stroke admissions sharply rising over time ( $p=0.012)$ due to the combined increases in the ICH and acute ischemic stroke, while TIA, SAH remain stable.

Panel B shows the age-adjusted stroke admissions rates. These are stable over time $(p=0.125)$. 


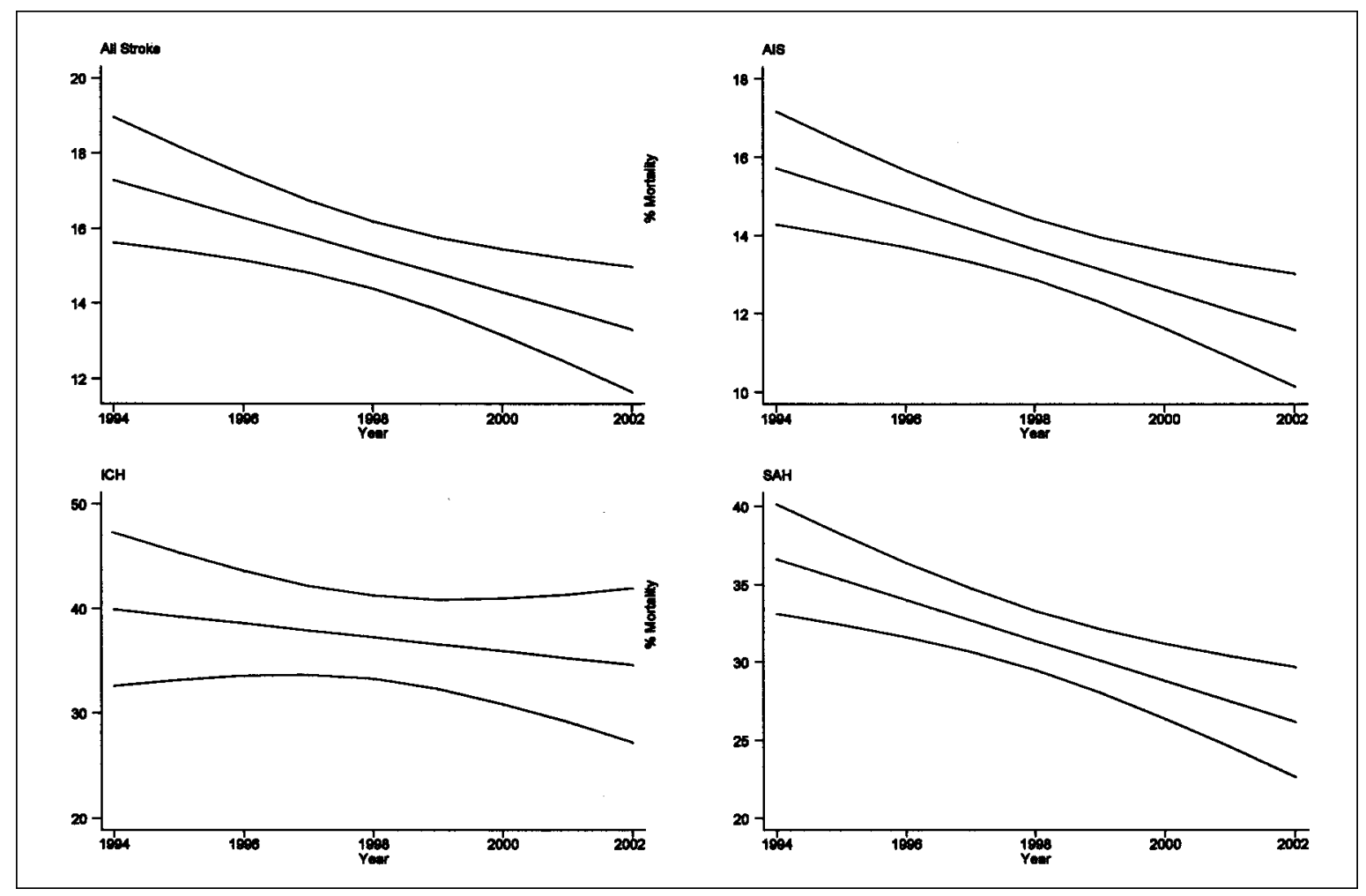

Figure 4: Trends in Stroke Percent In-hospital Mortality

Declining in-hospital mortality by stroke type. Clockwise from the top left are: All stroke, AIS, SAH, ICH..

and $1.4 \%$ for $\mathrm{SAH}$. Corresponding rates for ischemic stroke were $4.6 \%$ and $0.3 \% ; 0.6 \%$ and $0.2 \%$ for TIA. There were no instances of pulmonary thromboembolism/DVT or pneumonia associated with VS/CVT.

Age-adjusted rates of $\mathrm{ICH}$ admissions remained stable while $\mathrm{SAH}$ rates declined $(\mathrm{p}=0.042)$ (Figure 1 , panel $\mathrm{B})$. The absolute number of ICH admitted, however, increased overall $(\mathrm{p}=0.021)$ while numbers of SAH remained stable from year to year (Figure 1, Panel A).

Over the last nine years, age-adjusted admission rates for ischemic stroke have remained stable (Figure 2, Panel B). However, the absolute number of ischemic strokes admitted has increased sharply $(\mathrm{p}=0.011)$ (Figure 2, Panel A). Age-adjusted TIA admission rates have remained stable as well (Figure 2, Panel B), while the absolute number of TIA admissions to hospital has decreased slightly ( $\mathrm{p}=0.063$ ) (Figure 2, Panel A).

Overall, the rate of stroke admissions in the Calgary Health Region has remained stable over the past nine years $(p=0.125)$ (Figure 3, Panel B). However, total numbers of stroke admissions to hospital have faced a significant increase $(\mathrm{p}=0.012)$, due to the combination of increases in ICH and ischemic stroke admissions. Linear projections of this rate into the future imply an average increase of 47 strokes per year (95\%CI 14.0-79.6). With a conservatively estimated average length of stay of seven days per stroke event, every year an additional inpatient bed-day will be required to accommodate the increasing number of strokes in Calgary.
Although stroke admission rates remain constant, in-hospital stroke mortality has experienced an overall decline (Table 2, Figure 4). This is due to a decline in mortality from ischemic stroke, ICH and SAH (Figure 4). Intracerebral hemorrhages experienced a marked decline after 1997 and, overall, the decline is not statistically significant, while ischemic stroke mortality has increased slightly since 1999. Transient ischemic attack mortality has remained stable over the period of study.

In-hospital complication rates from DVT/PE have increased overall, with slight increases in hemorrhage cases and no change in rates seen amongst cases of ischemic stroke and TIA. Overall complication rates from pneumonia have remained stable, with an increase seen in TIAand a decline in SAH.

\section{Discussion}

Our data support corresponding data from western countries showing a declining stroke rate per population. However, an aging baby boomer demographic overwhelms this trend resulting in rapidly increasing utilization for stroke. This is expected and predicted. Because stroke is the leading cause of adult acquired disability and costs the Canadian economy over $\$ 3$ billion dollars annually, ${ }^{22}$ this observation has significant implications for Canadian hospitals and health systems.

In a previous study two decades ago using similar methodology to examine the entire Canadian population, ageadjusted rates of total stroke and stroke by each type were higher 
than our current numbers, particularly for ICH. ${ }^{23}$ The magnitude of decline was much less for acute ischemic stroke. This suggests that declines in stroke rates are actually occurring over time and that these declines are stroke type specific. One less wellexplained phenomenon is the declining rate of SAH. This was also observed in a previous 10-year Canadian study where the age-adjusted incidence of SAH declined over time and was nearly double what we report from Calgary. ${ }^{24}$ Absolute numbers of SAH may have remained stable over time in Calgary due to migration of working-age adults to the Calgary region. Subarachnoid hemorrhage peaks in the fifth decade of life and its most modifiable risk factor is smoking. ${ }^{25}$ Perhaps, as the baby boomer generation ages beyond the peak incidence, the number of SAH seen in Canadian hospitals will decline. Equally, declining rates of cigarette use in the population, particularly in the working adult population, may be contributing. ${ }^{26}$ Finally, neurosurgeons and endovascular neuroradiologists are able to discover and treat intracranial aneurysms before they rupture, potentially also leading to a declining rate of SAH. ${ }^{27-29}$ Since 1995, endovascular coiling for treatment of ruptured and unruptured intracranial aneurysm has become a widely used technique with 12000 patients treated worldwide with Guglielmi detachable coil in $1998 ;^{30}$ these numbers will likely increase following the recent publication of positive results from the International Subarachnoid Aneurysm Trial (ISAT). ${ }^{31}$

The decline in in-hospital deaths over time is a particularly encouraging observation. This is true for all stroke types but is most relevant for the most fatal stroke types - SAH and $\mathrm{ICH}$. This trend has been previously observed in Quebec. ${ }^{32}$ Ongoing improvements in pre-hospital care, emergency and neurocritical care are likely reasons for this observation, since no major therapeutic advances have been made in the specific surgical or medical care of ICH despite promising ongoing trials.

The fall in acute ischemic stroke mortality corresponds with development of active stroke intervention services in Calgary. While stroke thrombolysis was introduced in 1996 in Calgary, it has been applied to approximately $10 \%$ of patients annually and is, therefore, unlikely to be the major cause in the continuing fall in stroke mortality. Further, thrombolysis is a treatment that has not been shown to reduce stroke-related mortality but, instead, to reduce morbidity. ${ }^{33,34}$ More importantly, stroke services have been organized culminating in the opening of a 14-bed stroke unit in the city. Stroke unit care results in one less death for every 16 patients treated on a stroke unit. ${ }^{35}$ It is this organization of stroke care that may be the key factor in the falling death rates.

Neurological morbidity cannot be measured from administrative data. It is, nevertheless, probably more important than mortality. While declining mortality is assumed to imply declining morbidity, this is not necessarily true. If mortality is falling only to leave an increasing proportion of patients badly disabled, few would argue that this is a success because a majority of stroke survivors will report that they would prefer to be dead than badly disabled. ${ }^{36,37}$ This is an important future question for stroke epidemiological research.

Complication rates for DVT/PE and pneumonia have been static. Pneumonia rates remain high, particularly in hemorrhagic forms of stroke and this may be due to the higher rate of intubation and acute intensive care required for these patients. Symptomatic DVT/PE rates are very low, making it difficult to anticipate cases. Many DVTs may go undetected after stroke; however, PE accounts for a substantial minority of early deaths after stroke and may not be associated with clinically evident DVT antemortem. ${ }^{38-42}$

Our analysis has limitations. Because almost all patients with stroke are admitted to the hospital in Calgary, ${ }^{43}$ we assumed that hospital-based administrative data provide a good approximation of stroke occurrence. Nevertheless, although stroke tends to be well-coded compared to other medical conditions, the use of administrative data may have some limitations in diagnostic accuracy. Given that no distinction was made during the collection of administrative data, we considered both recurrent and first-ever stroke and we included in-hospital stroke. Changes in admission rates for stroke may also have been affected by changing thresholds for admission. While this is unlikely to have affected ICH, SAH or disabling ischemic stroke, it may well be important for minor ischemic stroke and TIA. It is interesting to note that the rate of admission for TIAhas been slowly falling.

It is possible that our assessment of in-hospital complications may be biased by underreporting due to the reduced sensitivity of ICD-9 diagnosis of cardiovascular and pulmonary complications. $^{44-46}$ Most importantly, stroke severity is an important unmeasured confounder and we could not measure it from administrative data. Because stroke severity is the most important predictor of outcome, our observation of declining mortality could be entirely or partly explained by a fall in the average severity of stroke. There is evidence to support biological reasons why stroke severity may be declining, including suggestive evidence for improving blood pressure control and treatment, ${ }^{47}$ declining cigarette use, ${ }^{26,48}$ and increased use of statin agents. ${ }^{49}$ Further investigation of trends in stroke severity as an explanation for declining stroke mortality is warranted.

Age-adjusted stroke incidence is falling but the absolute number of strokes is increasing in Calgary. This will result in increased utilization of health care resources over time. The increasing absolute numbers of stroke patients in Calgary are a model that can be used in administrative planning.

\section{ACKNOWLEDGEMENTS AND FUNDING:}

This project was supported in part by the Heart \& Stroke Foundation of Alberta/NWT/NT and the Calgary Health Region.

\section{REFERENCES}

1. Broderick JP. Stroke trends in Rochester, Minnesota, during 1945 to 1984. Ann Epidemiol 1993;3:476-479.

2. McGovern PG, Burke GL, Sprafka JM, et al. Trends in mortality, morbidity and risk factor levels for stroke from 1960 through 1990: The Minnesota Heart Survey. JAMA1992;268:752-759.

3. Lemesle M, Milan C, Faivre J, et al. Incidence trends of ischemic stroke and transient ischemic attacks in a well-defined French population from 1985 through 1994. Stroke 1999;30:371-377.

4. Truelsen T, Prescott E, Gronbaek M, Schnohr P, Boysen G. Trends in stroke incidence: the Copenhagen city heart study. Stroke 1997;28:1903-1907.

5. Brown RD, Whisnant JP, Sick JD, O'Fallon WM, Wiebers DO. Stroke incidence, prevalence and survival: secular trends in Rochester, Minnesota, through 1989. Stroke 1996; 27:373-380.

6. Pessah-Rasmussen H, Engström G, Jerntorp I, Janzon L. Increasing stroke incidence and decreasing case fatality, 1989-1998. Stroke 2003;34:913-918. 
7. Thorvaldsen P, Davidsen M, Brønnum-Hansen H, Schroll M. Stable stroke occurrence despite incidence reduction in an aging population: stroke trends in the Danish monitoring trends and determinants in cardiovascular disease (MONICA) population. Stroke 1999;30:2529-2534.

8. Heart and Stroke Foundation of Canada. Heart Disease and Stroke in Canada. Ottawa: Heart and Stroke Foundation of Canada; 1997.

9. Bata IR, Eastwood BJ, Gregor RD, et al. Decreasing mortality from acute myocardial infarctions: effect of attack rates and case severity. J Clin Epidemiol 1997;50:787-791.

10. Davies JW, Semenciw RM, Mao Y. Cardiovascular disease mortality trends and related risk factors in Canada. Can J Cardiol 1988;4 (Suppl A):16A-20A.

11. Uemura K, Pisa Z. Trends in cardiovascular disease mortality in industrialized countries since 1950. World Health Stat Q 1988;38:155-168.

12. Bonneux L, Looman CWN, Barendregt JJ, Van der Maas PJ. Regression analysis of recent changes in cardiovascular mobility and mortality in the Netherlands. Br Med J 1997;314:789-792.

13. Abildstrom SZ, Rasmussen S, Rosen M, Madsen M. Trends in incidence and case fatality rates of acute myocardial infarction in Denmark and Sweden. Heart 2003;89:507-511.

14. Messner T, Lundberg V. Trends in sudden cardiac death in the northern Sweden MONICA area 1985-99. J Intern Med 2003;253:320-328.

15. Sudlow CLM, Warlow CP. Comparable studies of the incidence of stroke and its pathological types: results from an international collaboration. Stroke 1997;28:491-499.

16. Korv J, Roose M, Kaasik AE. Changed incidence and case-fatality rates of first-ever stroke between 1970 and 1993 in Tartu, Estonia. Stroke 1996;27:199-203.

17. Sarti C, Stegmayr B, Tolonen H, et al, for the WHO MONICA Project. Changes in mortality from stroke caused by changes in stroke event rates of case fatality? Stroke 2003; 34: 1833-1841.

18. Broderick JP. Stroke trends in Rochester, Minnesota, during 1945 to 1984. Ann Epidemiol 1993;3:476-479.

19. McGovern PG, Burke GL, Sprafka JM, et al. Trends in mortality, morbidity and risk factor levels for stroke from 1960 through 1990: The Minnesota Heart Survey. JAMA1992;752-759.

20. Field TS, Hill MD. Stroke, chinook and the weather. Stroke 2002;33:1751-1778.

21. Yiannakoulias N, Svenson LW, Hill MD, et al. Regional comparison of inpatient and outpatient patterns of cerebrovascular disease diagnosis in the province of Alberta. Chronic Dis Can 2003;24:916.

22. Canadian Stroke Network. Facts Sheet. 2003. Available from: URL: http://www.canadianstrokenetwork.ca/media/downloads/fact.she et.e.pdf

23. Mayo NE, Neville D, Kirkland S, et al. Hospitalization and casefatality rates for stroke in Canada from 1982 through 1991. The Canadian Collaborative Study Group of Stroke Hospitalizations. Stroke 1996;27:1215-1220.

24. Ostbye T, Levy AR, Mayo NE. Hospitalization and case-fatality rates for subarachnoid hemorrhage in Canada from 1982 through 1991. The Canadian Collaborative Study Group of Stroke Hospitalizations. Stroke 1997;28:793-798.

25. Broderick JP, Viscoli CM, Brott T, et al. Major risk factors for aneurismal subarachnoid hemorrhage in the young are modifiable. Stroke 2003;34:1375-1381.

26. Statistics Canada. "Smoking." The Canada e-Book. Ottawa: Statistics Canada; 2001. Available from: URL: http://142.206.72.67/02/02b/02b_007a_e.htm. Accessed August 2003.

27. Willinsky RA. Detachable coils to treat intracranial aneurysms. Can Med Assoc J 1999; 161: 1136.

28. Lozier AP, Connolly ES Jr, Lavine SD, Solomon RA. Guglielmi detachable coil embolization of posterior circulation aneurysms: a systematic review of the literature. Stroke 2002;33:2509-2518.

29. Vallee JN, Aymard A, Vicaut E, Reis M, Merland JJ. Endovascular treatment of basilar tip aneurysms with Guglielmi detachable coils: Predictors of immediate and long-term results with multivariate analysis 6-year experience. Radiology 2003;226:867-879.

30. Willinsky RA. Detachable coils to treat intracranial aneurysms. Can Med Assoc J 1999;161:1136.

31. Molyneux A, Kerr R, Stratton I, et al. International Subarachnoid Aneurysm Trial (ISAT) of neurosurgical clipping versus endovascular coiling in 2143 patients with ruptured intracranial aneurysms: a randomised trial. Lancet 2002;360:1267-1274.

32. Mayo NE, Goldberg MS, Levy AR, Danys I, Korner-Bitensky N. Changing rates of stroke in the province of Quebec, Canada: 1981-1988. Stroke 1991;22:590-595.

33. The National Institute of Neurological Disorders and Stroke rtPA Stroke Study Group. Tissue plasminogen activator for acute ischaemic stroke. New Eng J Med 1995;333:1581-1587.

34. Wardlaw JM, del Zoppo G, Yamaguchi T. Thrombolysis for acute ischaemic stroke. The Cochrane Library 1999; Issue 4.

35. Stroke Unit Trialists' Collaboration. How do stroke units improve patient outcomes? A collaborative systematic review of the randomised trails of organised inpatient (stroke unit) care after stroke. Br Med J 1997;314:1151-1159.

36. Samsa GP, Matchar DB, Goldstein L, et al. Utilities for major stroke: results from a survey of preferences among persons at increased risk for stroke. Am Heart J 1998;136:703-713.

37. Solomon NA, Glick HA, Russo CJ, Lee J, Schulman KA. Patient preferences for stroke outcomes. Stroke 1994;25:1721-1725.

38. Hillbom M, Erila T, Sotaniemi K, et al. Enoxaparin vs heparin for prevention of deep-vein thrombosis in acute ischaemic stroke: a randomized, double-blind study. Acta Neurol Scand 2002;106:84-92.

39. Kelly J, Rudd A, Lewis R, Hunt BJ. Venous thromboembolism after acute stroke. Stroke 2001;32:262-267.

40. Muir KW, Watt A, Baxter G, Grosset DG, Lees KR. Randomized trial of graded compression stockings for prevention of deep-vein thrombosis after acute stroke. Q J Med 2000;93: 359-364.

41. Wijdicks EF, Scott JP. Pulmonary embolism associated with acute stroke. Mayo Clin Proc 1997;72:297-300.

42. Dumas R, Woitinas F, Kutnowski M, et al. A multicentre, doubleblind, randomized study to compare the safety and efficacy of once-daily ORG 10172 and twice-daily low-dose heparin in preventing deep-vein thrombosis in patients with acute ischaemic stroke. Age Ageing 1994;23: 512-516.

43. Hill MD, Barber PA, Demchuk AM, et al. Building a "brain attack" team to administer thrombolytic therapy for acute ischemic stroke. Can Med Assoc J 2000;162:1589-1593.

44. Proctor MC, Greenfield LJ. Pulmonary embolism: diagnosis, incidence and implications. Cardiovasc Surg 1997;5:77-81.

45. Espino JU, Wagner MM. Accuracy of ICD-9-coded chief complaints and diagnoses for the detection of acute respiratory illness. Proc AMIASymp 2001;164-168.

46. Marrie TJ, Durant H, Sealy E. Pneumonia--the quality of medical records data. Med Care 1987;25:20-24.

47. Campbell NR, McAlister FA, Brant R, et al for the Canadian Hypertension Education Process and Evaluation Committee. Temporal trends in antihypertensive drug prescriptions in Canada before and after introduction of the Canadian Hypertension Education Program. J Hypertens 2003; 21: 1591-1597.

48. Hamilton VH, Levinton C, St-Pierre Y, Grimard F. The effect of tobacco tax cuts on cigarette smoking in Canada. Can Med Assoc J 1997; 156: 187-191

49. Levy AR, O'Brien BJ, McMullen E, et al. Rapid increase in statins newly dispensed to Ontario seniors between 1994 and 2000. Can J Cardiol 2003; 9: 665-669. 